\title{
Extraction and Characterization of Cellulose and Cellulose Nanowhiskers from Almond Shell Biomass, Metal Removal and Toxicity Analysis
}

\author{
Sumira Rashid ${ }^{1(\mathbb{D})}$, Ankush Kumar Shahi ${ }^{2} \mathbb{D}$, Himjyoti Dutta ${ }^{3, * \mathbb{C}}$, Jatindra Kumar Sahu $4 \mathbb{( \mathbb { C }}$ \\ 1 Amity Institute of Food Technology, Amity University Uttar Pradesh, Sector 125, Noida, 201301, India; \\ sumirarashid219@gmail.com. (S.R); \\ 2 Department of Food Technology, Mizoram University, Aizawl, Mizoram, 796004, India; duttahimjyoti@gmail.com. \\ (H.D); \\ 3 Centre for Rural Development and Technology, Indian Institute of Technology Delhi, New Delhi, 110016, India; \\ Jatindra.Kumar.Sahu@ rdat.iitd.ac.in. (J.K.S.); \\ * Correspondence: duttahimjyoti@gmail.com; (H.D);
}

Scopus Author ID 38561243800

Received: 19.04.2021; Revised: 22.05.2021; Accepted: 25.05.2021; Published: 9.06.2021

\begin{abstract}
Almond shell is a major agro-industry waste. Cellulose is the major crystalline component of naturally porous almond shell biomass. In this study, cellulose (ASC) was isolated from almond shell (AS) by the dewaxing-alkali treatment-bleaching method, and nanocrystalline cellulose (ASN) was obtained by sulphuric acid hydrolysis of the obtained ASC. Separation efficiency was confirmed by Xray diffraction and IR absorption studies. ASC exhibited predominantly microporous monolithic structures under a scanning electron microscope. Its porosity resulted in significant absorption of $\mathrm{Cu}$ (II) and $\mathrm{Pb}$ (II) ions when applied as an absorbent in their solutions. Transmission electron microscopy and atomic force microscopy revealed the formation of ASN nanowhiskers with an average length and diameter of $170 \mathrm{~nm}$ and $20 \mathrm{~nm}$, respectively. Zeta potential of $-32.4 \mathrm{mV}$ suggested good colloidal dispersibility of the nanowhiskers. No hemolytic toxicity to erythrocyte cells was recorded, which suggested the potential applicability of the obtained nanomaterial in foods and pharmaceuticals. Remarkably high crystallinity and thermal resistance observed from calorimetry and thermogravimetry studies indicated enhanced density of the crystalline moiety during synthesis. ASC and ASN can be developed as effective metal absorption substrates and reinforcement agents in heat-resistant composite materials.
\end{abstract}

Keywords: almond shell; nanocellulose; thermal; toxicity; metal removal.

(C) 2021 by the authors. This article is an open-access article distributed under the terms and conditions of the Creative Commons Attribution (CC BY) license (https://creativecommons.org/licenses/by/4.0/).

\section{Introduction}

Cellulose is the most abundant structural biopolymer, generally extracted from the plant cell wall. It is composed of D-glucose units joined by linear $\beta-1,4$ glycosidic bonds. Its renewability, biocompatibility, mechanical properties, strength, and biodegradability have attracted significant technological attention in the field of material science and bio-waste management [1]. The crystallinity in semicrystalline cellulose is due to specifically ordered inter and intra-glycosidic chain interactions. The ratio of crystalline fractions to disordered amorphous regions in the polymeric matrix is a function of its origin [2]. Six distinct allomorphic forms of cellulose, namely cellulose I, II, IIII, IIIII, IVI, and IVII have been identified [3]. Of these, cellulose I and II are highly abundant in nature and identified by their 
infrared absorption and X-ray diffraction patterns. Inter-conversion of allomorphism in cellulose can occur during chemical and thermal processing. Variation in extraction and synthesis conditions can result in marked differences in physical and physicochemical characteristics of cellulose and its derivatives.

Nanocrystalline cellulose (NCC) is considered the most popular physical derivative of cellulose [4]. Amorphous and crystalline domains are arranged alternately within the semicrystalline matrix of cellulose. Hydrolysis by diluted acids results in selective dissociation of amorphous fractions and release of the crystalline structures as NCC particles. Targeted applications of NCCs owe to their small size, high strength, crystallinity, surface area, aspect ratio, and thermostability [5]. Being biodegradable and inert, cellulose and NCC have been used in food and pharmacological appliances [6]. NCC-based primary packaging films have been successfully developed [7]. Although biological nanomaterials are generally considered safe, corrosive chemicals like acids during their synthesis may impart toxic properties. Toxicity to human cell systems must be analyzed to ensure safety. Nanoparticles, being very small in size, may easily interfere with erythrocyte cells once they entered the bloodstream, causing conditions like anemia and jaundice. Our previous studies analyzed and reported on the nontoxicity of rice husk NCC and applied derivatized carboxymethylcellulose as an effective thickness stabilizer in yogurt [8,9]. Stabilizing effect on microencapsulation systems can also be imparted by ASN, indicating probable use in food and pharmaceutical targeted delivery systems [10].

NCCs have been synthesized from cellulose extracted from a vast range of plant parts [11-17]. Almond (Prunusdulcis sp.) contains an edible fleshy seed covered in a hard shell. The shell is cracked open to obtain the seed. Almond shell constituting about $50 \%$ of the total fruit weight is a low-cost, porous, and pitted lightweight waste material. Its popular management approaches include landfilling, animal feed, bedding material, and use as fuel for the boiler. Shell powder has been used as reinforcing filler in various composite materials [18], as growing material for soilless vegetable production [19], and for producing activated carbon [20]. Biosorbent materials are popular due to their bulk availability, non-toxicity, and biodegradability. Almond shell has been used as heavy metal and dye absorbent [21-23]. The shell possesses piths formed by lignified thick-walled sclereid cells of sclerenchyma tissue [24]. Almond shell is a rich source of lignocellulosic components. Functional polysaccharides in the material need to be characterized for the prospective value addition of this food industry waste. A cellulose composition of more than $29 \%$ makes almond shell a suitable raw material for cellulose and nanocellulose extraction [25]. Variations in extraction technique parameters could be found in the few available studies [26-28]. Method and process conditions, namely time, temperature, and solvent concentration, play decisive roles in yield, shape, size, and physicochemical characteristics, including those from almond shells [29-31]. For example, the shape of NCCs can vary from whisker, rod-shaped, or spherical. Accordingly, particle sizes can also differ [27,29]. Aspect ratio and degree of crystallinity curb the targeted application of nanocrystalline cellulose [32]. Nanofibers and nano-spheres of almond shell NCC have been reported by Maaloul et al. (2017) and Urruzola et al. (2014), respectively [27,29]. Use of 64\% or higher concentrations of sulphuric acid has been reported to be ideal to obtain cellulose nanowhisker, a shape which has never been reported for almond shell NCC [1]. Composite beads formed by crosslinking ASN fibers with sodium trimetaphosphate acted as an effective biosorbent in a study [33]. In a more recent report, the authors have developed a roughly sphereshaped biopolymer composite of almond shell cellulose nanocrystals by the dissolution of the 
primary particles in 1-butyl-3-methylimidazolium chloride to find them as effective adsorbent of $\mathrm{Cu}$ (II) with absorption capacity as high as $131.16 \mathrm{mg} / \mathrm{g}$ in batch process and up to $81 \%$ ion removal after four cycles of repeated adsorption and desorption [34]. Similarly, Shu et al. (2020) used iron biochar-derived AS for removing hexavalent chromium ions [35]. Chromium ion and Orange $\mathrm{G}$ dye removal using polyaniline-AS biomass composite were also reported [36]. These were partially indicative of and hence created the major scope for doing adsorption studies on cheaper, un-derivatized native materials, namely almond shell powder, cellulose, and nanocellulose on multiple toxic metal ions in industrial wastewater streams.

In this research, almond shell cellulose (ASC) was extracted by alkaline processing and bleaching of almond shell (AS) powder followed by reduction to nanowhiskers (ASN) using a $68 \%$ solution of sulphuric acid. AS, ASC, and ASN were studied for changes in their physicochemical properties, toxicity on erythrocyte cells, and applicability as copper and lead metal absorbent biomaterials

\section{Materials and Methods}

\subsection{Materials.}

Almond shells (AS) procured from an almond seller from New Delhi, India was washed repeatedly with distilled water followed by air drying at $50{ }^{\circ} \mathrm{C}$ for $24 \mathrm{~h}$. The shells were pulverized and passed through sieves to obtain flour with 150 to $210 \mu \mathrm{m}$ particle sizes. Milled almond shell particles' size can directly affect the extractability of cellulose [31]. The particulate powder samples were stored in a high-density polyethylene container till further use. Analytical grade chemicals were purchased from HiMedia (India), dialysis membranes from Sigma-Aldrich (USA), and glassware from Borosil (India).

\subsection{Methods.}

2.2.1. Isolation of cellulose.

Cellulose was isolated from AS powder using modifications of available methods [11, 37-39]. Briefly, the powder was first dewaxed by the soxhlet method using a mixture of benzene and methanol $(1: 1)$ at $80{ }^{\circ} \mathrm{C}$ for $8 \mathrm{~h}$. After evaporating the residual solvent, $100 \mathrm{~g}$ of dewaxed powder was mixed with $400 \mathrm{ml}$ sodium hydroxide solution (3\%, w/v) and autoclaved $\left(121^{\circ} \mathrm{C}, 15 \mathrm{psig}\right)$ for $8 \mathrm{~h}$. This treatment weakened the bonds between different non-cellulosic components and was repeated twice to ensure better separation. The alkali solution was then strained, and the residual material was washed ten times with distilled water to get rid of all adhering alkali. It was then subjected to bleaching thrice with a solution containing $27 \mathrm{~g} \mathrm{NaOH}$, $75 \mathrm{~g}$ glacial acetic acid, and $17 \mathrm{~g}$ sodium hypochlorite in $1000 \mathrm{ml}$ distilled water, each time for 8 hours in an orbital shaker. Bleaching resulted in delignification of the holocellulose material and solubilization of the non-cellulose components. Off-white-colored neutral ASC was obtained after washing several times with distilled water. The material was dried at $70{ }^{\circ} \mathrm{C}$ for $24 \mathrm{~h}$ to $5 \%$ moisture content and stored in an air-tight container.

\subsubsection{Preparation of nanowhiskers.}

For nanowhisker production, $5 \mathrm{~g}$ ASC was treated with $147 \mathrm{ml}$ of a sulphuric acid solution $\left(68 \% \mathrm{w} / \mathrm{w}, 1: 20 \mathrm{ASC}\right.$ to acid ratio) at $40{ }^{\circ} \mathrm{C}$ for $90 \mathrm{~min}$ with stirring at $1500 \mathrm{rpm}$. The reaction was terminated by pouring the reaction mixture into 1 liter of chilled distilled water. 
The solution was centrifuged at $8000 \mathrm{rpm}$ for $10 \mathrm{~min}$. The obtained aliquot was dialyzed against millipore water till neutrality. The suspension was sonicated $(300 \mathrm{~W})$ in an ice bath for $30 \mathrm{~min}$, frozen at $-40{ }^{\circ} \mathrm{C}$, and then lyophilized for $72 \mathrm{~h}$ to ASN particles.

\subsubsection{Chemical composition and yield.}

Chemical compositions of AS and ASC were analyzed by the methods described by de Oliveira et al. (2017) [40]. Lignin was determined by the TAPPI T13m-54 procedure as described by Song et al. (2020) [41]. Briefly, a suspension carrying $1 \mathrm{~g}$ of a powder sample in $20 \mathrm{ml}$ sulphuric acid (72\%) was magnetically stirred for $24 \mathrm{~h}$. The leftover residue containing insoluble lignin and ash was collected by filtering the suspension through a reweighted sintered glass funnel (Borosil, G4) and consequently dried $\left(70{ }^{\circ} \mathrm{C}, 24 \mathrm{~h}\right)$ and weighed. Holocellulose (cellulose + hemicellulose) and cellulose contents were determined as per Song et al. (2020) [41]. A suspension carrying powdered sample (3 g), sodium hypochlorite ( $2.5 \mathrm{~g})$, glacial acetic acid $(1 \mathrm{ml})$, and distilled water $(120 \mathrm{ml})$ was maintained at $70^{\circ} \mathrm{C}$ in a water bath with stirring for $1 \mathrm{~h}$. The sequence was repeated twice with the addition of a fresh solution. After storing at $4{ }^{\circ} \mathrm{C}$ for $3 \mathrm{~h}$, the supernatant containing suspended holocellulose material was filtered through sintered glass funnel, washed rigorously with distilled water followed by methanol, and dried at $40{ }^{\circ} \mathrm{C}$ in a vacuum oven till constant weight. Ash content was determined by a standard AOAC (2006) method [42].

\subsubsection{Yield of nanocrystalline cellulose.}

The yield of ASN in sample suspension was determined gravimetrically [12]. A measured aliquot volume was taken and dried at $90{ }^{\circ} \mathrm{C}$ for $24 \mathrm{~h}$ in a hot air oven. The yield was determined by the ratio of the mass left after drying to the representative mass of AS taken for its preparation.

\subsubsection{Electron microscopy.}

The morphologies of AS and ASC samples were observed under a scanning electron microscope (SEM, model EVO-18, Zeiss, Germany). Powder samples were fixed on doublesided adhesive carbon tapes, vacuum dried, sputter-coated with gold (Au), and scanned at an accelerating voltage of $20 \mathrm{kV}$ under 5000x magnification. A transmission electron microscope (TEM, XFlash 6T130, Bruker, USA) operating at $120 \mathrm{kV}$ voltage was used to assess the surface dimensions of the ASN particles at higher magnifications. A drop of $0.2 \%$ aqueous suspension of ASN was deposited on a copper grid (360 mesh) and allowed to dry under a vacuum. The copper grid was then inserted into the instrument, and magnified images were captured.

\subsubsection{Atomic force microscopy.}

An atomic force microscope (AFM, NT-MDT, SOLVER NANO, Russia) was used to capture 2D and 3D surface images of ASN particles. The sample was prepared by depositing a drop of $1 \%$ aqueous suspension of ASN on a glass slide, followed by drying. Tapping mode scanning was performed using a standard silicon probe at room temperature $\left(\mathrm{RT}=25 \pm 2{ }^{\circ} \mathrm{C}\right)$.

\subsubsection{Zeta potential.}

The value of zeta potential indicates the surface charge of nanoparticles, suggesting their electrophoretic mobility. An aqueous suspension $(0.005 \%, \mathrm{w} / \mathrm{w})$ of the freeze-dried ASN 
particles was analyzed in a Zeta Sizer Nano ZS (Malvern Panalytical, UK) instrument at RT, applying a wavelength of $659 \mathrm{~nm}$.

\subsubsection{Infrared spectroscopy.}

A Fourier transform infrared (FTIR) spectrometer (Cary 630 FTIR, Agilent Technologies, USA) with $\mathrm{KBr}$ optics was used to estimate the chemical bonding patterns of AS, ASC and ASN (1:100, sample:KBr). Scanning was performed within the wavenumber range of $400-4000 \mathrm{~cm}^{-1}$ at a resolution of $4.0 \mathrm{~cm}^{-1}$, using inbuilt Resolution Pro software (version 2.5.5, Agilent Technologies, USA) to obtain the absorption data.

\subsubsection{X-ray diffraction.}

Wide-angle X-ray diffraction (XRD) was performed to determine the crystallinity of the samples. A MiniFlex 600 (Rigaku) instrument with $\lambda=1.54$, acceleration potential $=40$ $\mathrm{kV}$, current $=15 \mathrm{~mA}$ fitted with a copper target was used to measure the diffraction over a scanning range of $2 \theta=2^{\circ}$ to $60^{\circ}$ at a scan speed of $3 \% \mathrm{~min}$. Percentage crystallinity (Xc) was determined using the amorphous subtraction method [11].

$$
\mathrm{X}_{\mathrm{C}}=\mathrm{A}_{\mathrm{c}} /\left(\mathrm{A}_{\mathrm{C}}+\mathrm{A}_{\mathrm{m}}\right) \times 100
$$

Where $X_{c}=$ percentage crystallinity

$A_{c}=$ area under crystalline peaks

$\mathrm{A}_{\mathrm{m}}=$ area under the amorphous portion

The crystallinity index (CrI) was determined according to the Segal equation (Segal, Creely, Martin, \& Conrad, 1959) as

$$
\mathrm{CrI}=\left(\mathrm{I}_{200}-\mathrm{I}_{\mathrm{am}}\right) / \mathrm{I}_{200} \times 100
$$

Where,

$\mathrm{I}_{200}=$ intensity of the crystalline peak corresponding to crystalline plane $200\left(2 \theta=22.7^{\circ}\right)$

$\mathrm{I}_{\mathrm{am}}=$ intensity of the amorphous peak between crystalline planes 200 and $110\left(2 \theta=18.8^{\circ}\right)$

Average crystal thickness ( $\mathrm{t}$ ) of cellulose I was determined using Scherrer's equation

$$
\mathrm{t}=\mathrm{K} \lambda / \beta \operatorname{Cos} \theta
$$

Where,

$\mathrm{K}=$ correction factor value of 0.91

$\lambda=0.154 \mathrm{~nm}$

$\theta=$ diffraction angle

$\beta=$ full width at half maximum of the peak corresponding to crystalline plane 200

2.2.10. Thermogravimetric analysis.

The samples' thermal degradation-dependent weight loss patterns were assessed using a thermogravimetric analyzer (TGA, TG209 F3 Tarsus, NETZSCH) under $\mathrm{N}_{2}$ atmosphere. Approximately $10 \mathrm{mg}$ of powder sample was heated from $20^{\circ} \mathrm{C}$ to $600{ }^{\circ} \mathrm{C}$ at a rate of $20^{\circ} \mathrm{C} / \mathrm{min}$ under a gas flow rate of $60 \mathrm{ml} / \mathrm{min}$.

\subsubsection{Differential scanning calorimetry.}

Differential scanning calorimetry (DSC) of the samples was carried out using a DSC-1 STAR $^{\mathrm{e}}$ System (Mettler Toledo, USA). The machine was periodically calibrated by flushing with standard indium for heat flow and temperature. Approximately $10 \mathrm{mg}$ sample was taken 
in a hermetically sealed DSC pan, heated from $20{ }^{\circ} \mathrm{C}$ to $500{ }^{\circ} \mathrm{C}$ at a rate of $10{ }^{\circ} \mathrm{C} / \mathrm{min}$ under $\mathrm{N}_{2}$ atmosphere against an empty reference pan. The onset (To), peak (Tp), and conclusion (Tc) temperatures and enthalpy of crystallite melting $(\Delta \mathrm{H}, \mathrm{J} / \mathrm{g})$ were recorded from the thermal transition curve generated by the inbuilt software.

\subsubsection{Hemolytic activity.}

The hemolytic activity of nanomaterials suggests their toxicity. Kalita et al. (2015) described a method slightly modified to measure the hemolytic activity of ASN [44]. Briefly, fresh goat blood was collected in a sodium heparin-coated tube, centrifuged at $5000 \mathrm{rpm}$ for 5 minutes, and the supernatant discarded. The precipitate containing erythrocyte cells was washed twice with sterile phosphate buffer saline (PBS, $\mathrm{pH}=7.4$ ). Two milliliters of the solution were transferred to a tube containing $5 \mathrm{mg}$ of ASN, and volume was made up to $50 \mathrm{ml}$ with phosphate buffer. Another tube with $0.2 \%$ Triton X-100 was also inoculated with the same volume of erythrocytes, considering the complete lysis of the cells. After 80 min of incubation at $37^{\circ} \mathrm{C}$, the tubes were centrifuged ( $5000 \mathrm{rpm}$ for 5 minutes), and the supernatants' absorbance was recorded at $415 \mathrm{~nm}$. The absorbance of PBS was the negative control. Hemolysis percentage $(\mathrm{H}, \%)$ was calculated using the equation

$$
\mathrm{H}=\left[(\mathrm{As}-\mathrm{An}) /\left(\mathrm{A}_{100}-\mathrm{An}\right)\right] \times 100
$$

Where,

As $=$ Absorbance of ASN hemolysed sample

$\mathrm{A}_{100}=$ Absorbance of Trion X-100 hemolysed sample

An $=$ Absorbance of negative sample

2.2.13. Metal sorption property.

AS, ASC, and ASN powders were assessed for their copper and lead absorption capacity by a batch method modified from Ronda et al. (2013) [45]. Two metal solutions were prepared by dissolving $1 \mathrm{~g}$ of $\mathrm{Cu}\left(\mathrm{NO}_{3}\right)_{2} \cdot 3 \mathrm{H}_{2} \mathrm{O}$ and $\mathrm{Pb}\left(\mathrm{NO}_{3}\right)_{2}$ in $1000 \mathrm{ml}$ distilled water. $100 \mathrm{ml}$ portions of these solutions were taken in $150 \mathrm{ml}$ conical flasks, and $1 \mathrm{mg}$ powder samples were added, $\mathrm{pH}$ adjusted to 5.0 , and incubated at $25 \pm 1{ }^{\circ} \mathrm{C}$ for $120 \mathrm{~min}$ in a shaking incubator. After filtration, final concentrations of $\mathrm{Cu}$ (II) and $\mathrm{Pb}$ (II) in the solutions were measured by atomic absorption spectrometry (AAS-ICE 3500, Thermo Scientific, UK), and the percentage of ion removal was calculated.

\section{Results and Discussion}

\subsection{Chemical composition and yield of fibers.}

Weight-based compositions of $\alpha$-cellulose, hemicellulose, lignin, and ash in AS were $32.46 \%, 29.54 \%, 31.70 \%$, and $3.10 \%$, respectively. The isolation process and process variables decide the final yield of cellulose from its source [30]. A comparison of these values to those reported by other authors using different extraction methods is given in Table 1. ASC had a cellulose content of $90.24 \%$ and hemicellulose and lignin proportions of $4.78 \%$ and $0.56 \%$, respectively, suggesting efficient removal of non-cellulosic components during alkali and acid treatments used in this synthesis method. 
Table 1. Composition (average, weight basis \%) of cellulose and non cellulosic components recorded for almond shell biomass in different studies.

\begin{tabular}{l|l|l|l|l} 
Cellulose & Hemicellulose & Lignin & Ash & References \\
\hline 32.46 & 29.54 & 31.70 & 3.10 & Present study \\
\hline 29.90 & 25.10 & 30.10 & 3.40 & {$[27]$} \\
\hline 29.10 & 35.20 & 32.70 & 3.40 & {$[25]$} \\
\hline 50.70 & 26.40 & 20.40 & 1.63 & {$[24]$} \\
\hline 40.50 & 19.70 & 27.20 & - & {$[59]$}
\end{tabular}

\subsection{Yield of nanocellulose.}

The yield of ASN was $41.53 \%$, which suggested maximum removal of amorphous fractions, indicating an efficient time, temperature, and acid concentration combination for cellulose hydrolysis. The yield was higher than previously reports on nanocrystalline cellulose extracted from coconut husk (12.0\%), soy hull (20.0\%), pinewood $(2.3 \%)$ and corn cob $(6.0 \%)$ $[12,46,47]$ and lower than those extracted from cotton linters $(74.5 \%)$, spruce wood $(61 \%)$, Chinese silver grass (55.6\%), eucalyptus wood (63\%) and sugarcane bagasse $(50-58 \%)[48,49]$.

\subsection{Scanning electron microscopy.}

Morphological features of 5000x magnified AS and ASC samples are shown in Figure 1 ( $a, b$, and c). AS exhibited a smooth, uniformly dotted surface. The dotted layer was removed during dewaxing and delignification. ASC mostly exhibited pitted and porous monolithic structures with pore sizes ranging between $0.8 \mu \mathrm{m}$ to $2.0 \mu \mathrm{m}$ and very few rod-like structures (Figure 1 b, c). Khili et al. (2018) reported the occurrence of only rod-like fibrillary structures with breadth and length of $10-20 \mu \mathrm{m}$ and $80 \mu \mathrm{m}$ respectively, which were further composed of nano-rods held together [26]. Delignification in their method involved high temperature, which could cause degradation of the basic porous cellulose bodies. The porous structures dominated the scan area in the present study, even after multiple repetitions of extraction and SEM observation.

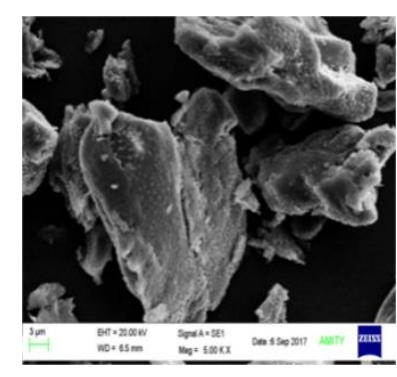

a

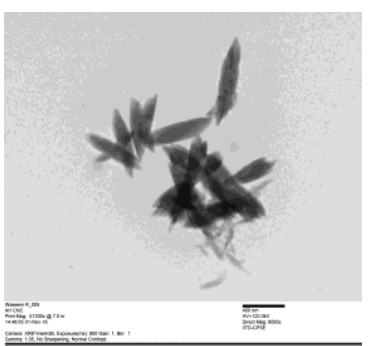

d

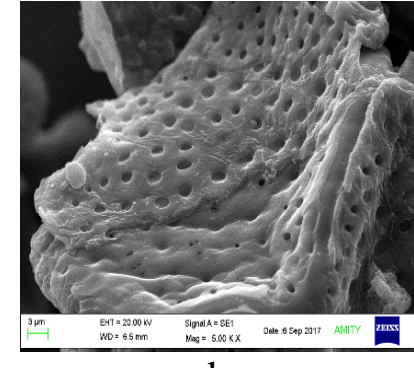

b

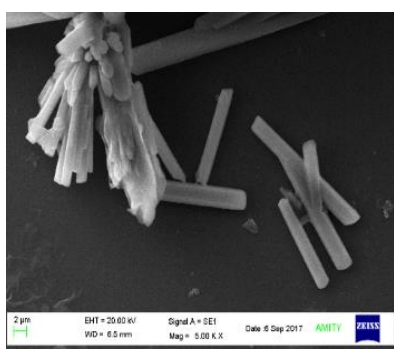

c

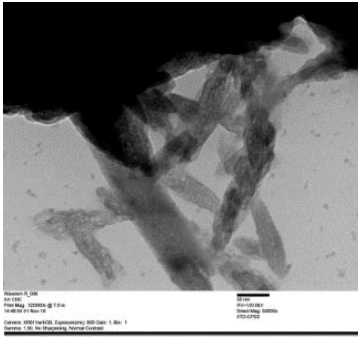

e

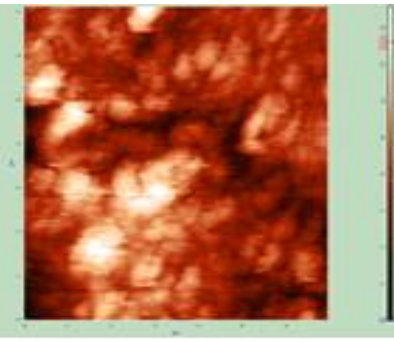

f

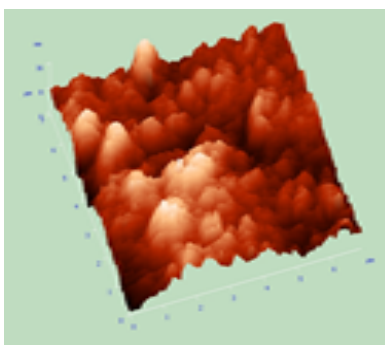

g

Figure 1. 5000x SEM micrographs of (a) AS; (b) ASC porous structures; (c) ASC rod structures; (d) 8000x and (e) 50000x TEM micrographs of ASN; (f) 2D; (g) 3D AFM images of ASN. 
It was opined that cellulose fibers in AS repeatedly interlock with each other, forming its naturally porous surface. This peculiar structure of ASC is being reported for the first time. Porous cellulose monoliths could be a suitable absorbent substrate for separation, purification, and biocatalysis. This microporous structure could be considered the factor behind almond shell biomass's high absorption efficiency [21].

\subsection{Transmission electron microscopy.}

Roughly spindle-shaped whisker structures with lengths ranging from $130 \mathrm{~nm}$ to 470 $\mathrm{nm}$ and diameter from $10 \mathrm{~nm}$ to $30 \mathrm{~nm}$ were observed under TEM (Figure $1 \mathrm{~d}$, e). This was contrary to previous reports [27, 34], which reported $200 \mathrm{~nm}$-sized spherical structures of ASN particles. Differences in hydrolytic acid concentration, temperature, and time have been related to differences in nanoparticle morphology [50]. The nanowhiskers exhibited a trivial clustering tendency due to H-bonding [11]. At 50000x magnification, ASN exhibited transparency, suggesting porosity (Figure $1 \mathrm{e}$ ). Hence, the typical lightweight of almond shell biomass could be attributed to extensive porosity ranging from macro, micro, to nano-scales of its natural construction.

\subsection{Atomic force microscopy.}

Both 2D and 3D AFM images of ASN exhibited spindle-like structures with ovalshaped smooth central portions (Figure $1 \mathrm{f}, \mathrm{g}$ ). As was also observed under TEM, aggregation of particles at endpoints caused limited aberration in structural distinctiveness in the AFM images. Particle lengths recorded between $230 \mathrm{~nm}$ to $450 \mathrm{~nm}$ were within the size range observed under TEM.

\subsection{Zeta potential.}

The stability of nanoparticles in aqueous colloidal suspension is determined by their surface charges. ASN presented an average zeta potential of $-32.4 \mathrm{mV}$. The application of sulphuric acid for hydrolysis causes sulfate esterification of hydroxyl groups of the cellulose molecules [51]. The presence of negative charges results in electric repulsion, restricting them from coagulating. This substantially negative zeta potential value (lower than $-25 \mathrm{mV}$ ) suggested good colloidal stability of the nanoparticles, as was also indicated by the limited selfadherence of the particles prepared for TEM and AFM studies [52]. This property could make way for ASN in applications requiring suspension of the bio-nanomaterial in the aqueous phase.

\subsection{Functional groups.}

FTIR spectra of AS, ASC, and ASN are shown in Figure 2. Characteristic bands of cellulose were observed for all samples. The prominent peaks at $1517 \mathrm{~cm}^{-1}, 1589 \mathrm{~cm}^{-1}$, and $1234 \mathrm{~cm}^{-1}$ bands in AS were ascribed to the unsaturated linkages and $\mathrm{C}=\mathrm{C}$ stretching vibrations of aromatic ring structures of lignin [11,13]. Another band at $1734 \mathrm{~cm}^{-1}$ of AS is associated with the $\mathrm{C}=\mathrm{O}$ stretching of acetyl and uronic ester groups of hemicellulose and xylans or carboxylic group ester linkages of ferulic and p-coumaric acids in lignin [40,53]. The absence of all these bands and increased prominence of the band at $2921 \mathrm{~cm}^{-1}(\mathrm{C}-\mathrm{H}$ stretching vibration of cellulose) for ASC and ASN depicted successful removal of non-cellulosic components during delignification $[14,48]$. In holocellulose matrix, these components inhibit inter-cellulose 
H-bonding. The broad peak between $3000-3700 \mathrm{~cm}^{-1}$, associated with $-\mathrm{OH}$ stretching vibration of cellulose, became sharper in ASC and ASN, suggesting a higher concentration of purer cellulose per unit of matrix space. Absorption bands at $1432 \mathrm{~cm}^{-1}, 1060 \mathrm{~cm}^{-1}$, and $897 \mathrm{~cm}^{-1}$ which were characteristic of $-\mathrm{CH}_{2}-\left(\mathrm{C}_{6}\right)$ - bending, C-O stretching of pyranose ring, and bending vibration of $\beta$-glycosidic linkages, respectively, were depictive of unaltered cellulose I structure [11].

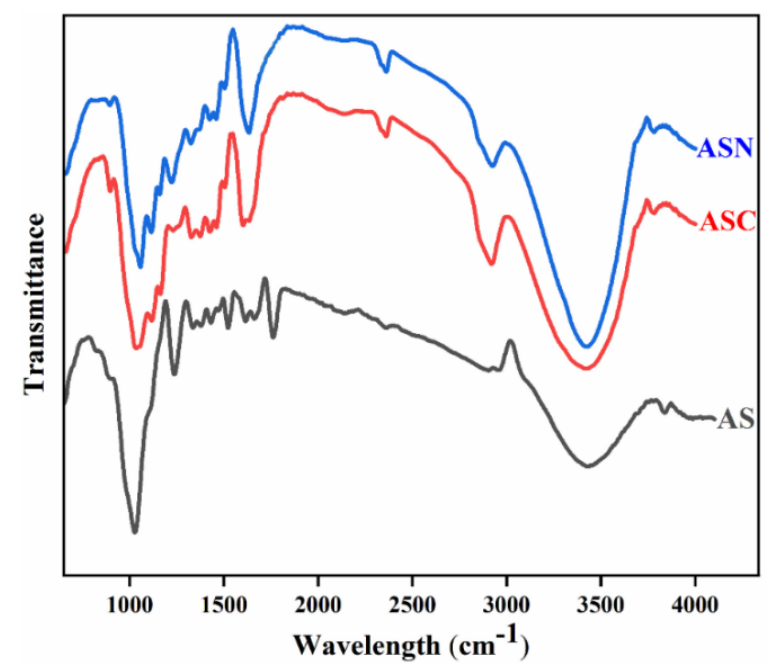

Figure 2. FTIR spectra of AS, ASC, and ASN.

\subsection{X-ray diffraction.}

XRD graphs of AS, ASC, and ASN are presented in Figure 3. AS exhibited major diffraction peaks at $2 \theta$ values of $16.4^{\circ}, 21.6^{\circ}$, and $35.0^{\circ}$. The peak at $21.6^{\circ}$ shifted to $22.7^{\circ}$ in ASC and ASN and developed distinct prominence. This shift could be attributed to the removal of hemicellulose and lignin portions from the crystalline matrix of holocellulose that are known to cause crystalline diffraction interference $[16,50]$.

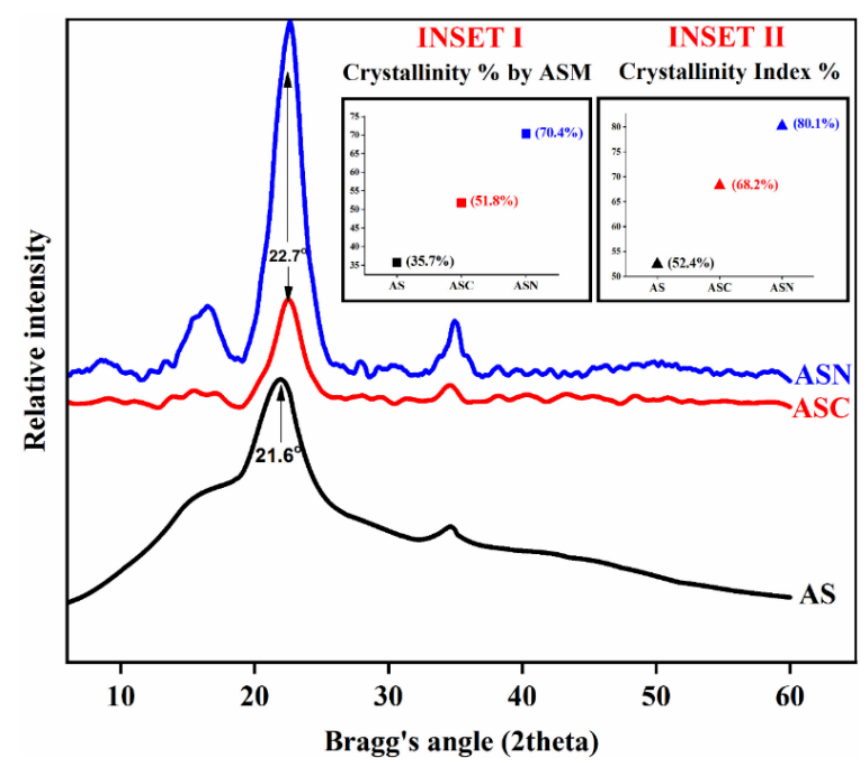

Figure 3. XRD curves of AS, ASC, and ASN. Crystallinity (\%) and crystallinity index (\%) are plotted in insets I and II, respectively.

Significant increase in Xc from AS (35.7\%) to ASC (51.8\%) and enhanced prominence of all the three peaks occurred due to the removal of largely amorphous lignin and 
hemicellulose (Figure 3 Inset I). Cellulose I crystal structure with 110, 200, and 004 diffraction planes were thereby confirmed [54]. No allomorphic transformation was found with the prevalence of cellulose I throughout the synthesis process. ASN showed the highest Xc value of $70.4 \%$ due to removing hydrolyzed amorphous portions of cellulose. Values of CrI for AS, ASC, and ASN were $52.45 \%, 68.21 \%$, and $80.15 \%$, respectively (Figure 3 Inset II). This was in accordance with the result of ASN yield and FTIR study, which indicated a more compact packing of cellulose crystallites in ASN. The value was higher than the crystallinity percentage of ASN reported by Maaloul et al. [27,34]. The crystal thickness of ASN corresponding to the crystalline plane 200 was calculated to be $6.29 \mathrm{~nm}$, which was also supported by the TEM results.

\subsection{Thermal properties.}

The TGA thermograms of AS, ASC, and ASN are shown in Figure 4 (a). Each sample showed an initial weight loss below $100{ }^{\circ} \mathrm{C}$, which was assigned to the release of partially bound inter and intramolecular chemisorbed water [55]. Thermal degradation of vapor-free AS, ASC, and ASN initiated at Tonset of $224^{\circ} \mathrm{C}, 245^{\circ} \mathrm{C}$, and $220^{\circ} \mathrm{C}$, respectively. This second stage of weight loss corresponds to multistep thermal degradation (decoiling + depolymerization + intermolecular dehydration + decomposition) of glycosidic chains. Lower Tonset of AS was attributed to the early decomposition of hemicellulose and lignin with lower structural stability than cellulose. The increased proportion of cellulose in ASC was reflected by a sharper drop in percentage mass than AS [56]. ASN showed the lowest $\mathrm{T}_{\text {onset }}\left(220^{\circ} \mathrm{C}\right)$ but exhibited the longest retention of structural integrity with $\mathrm{T}_{\max }$ value of $463{ }^{\circ} \mathrm{C}$. This was higher than $\mathrm{T}_{\max }$ of ASC $\left(359.4{ }^{\circ} \mathrm{C}\right)$ and AS $\left(382.1{ }^{\circ} \mathrm{C}\right)$. Sulfate esterification of cellulose nanoparticle surfaces causes alteration in size and density of the crystalline moiety [57]. In the TGA curve of ASN, the second stage of thermal degradation had two distinct sub-stages. The second sub-stage ranging from $344{ }^{\circ} \mathrm{C}$ to $463{ }^{\circ} \mathrm{C}$ was contributed by degradation of the lowest molecular weight carbonic residual components in ASN [11].

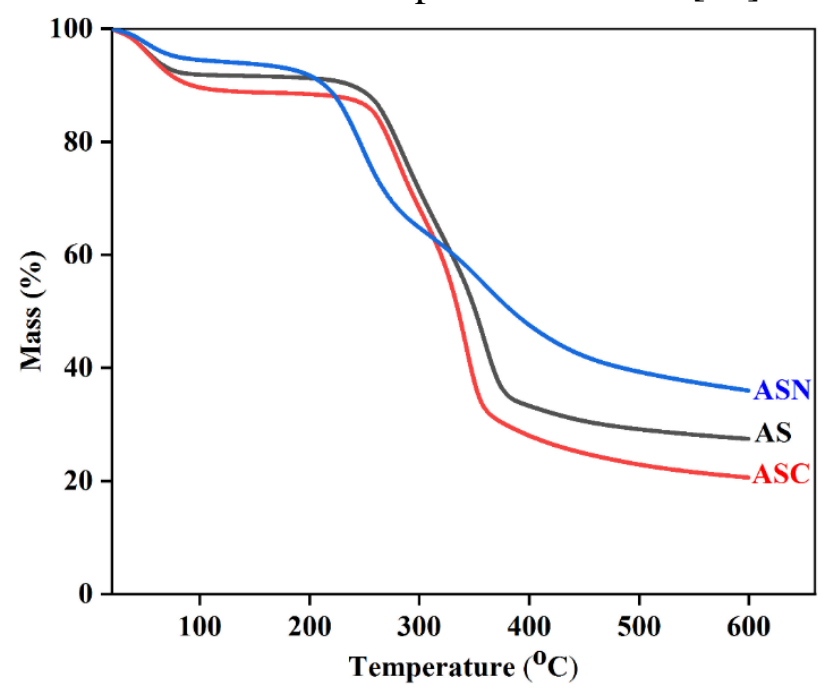

$\mathbf{a}$

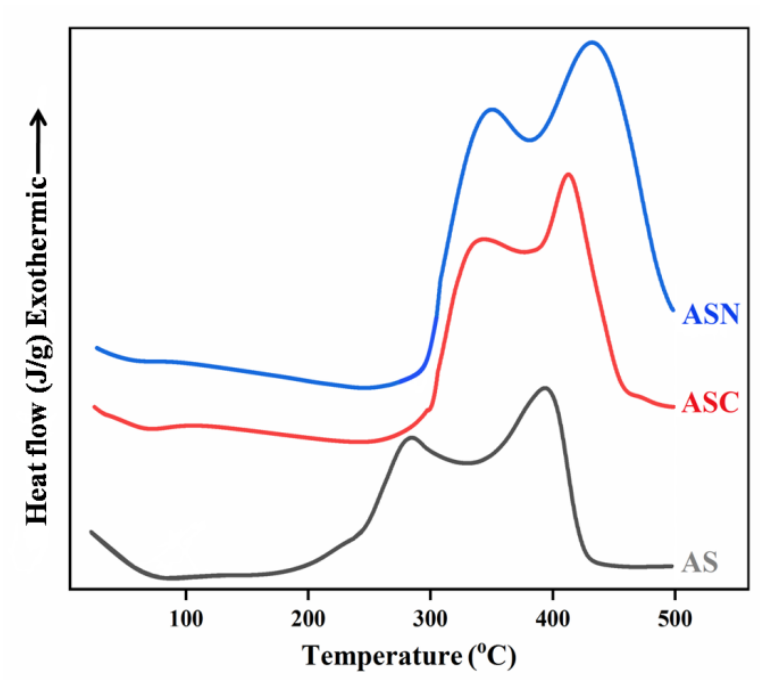

b

Figure 4. (a) TGA; (b) DSC curves of AS, ASC and ASN samples.

Two endothermic peaks were observed in each DSC thermogram (Figure $4 \mathrm{~b}$ ). The first peak below $130{ }^{\circ} \mathrm{C}$ was contributed by the evaporation of bound water $[11,55]$. The second 
peak within the range of $300-450{ }^{\circ} \mathrm{C}$ was associated with the pyrolysis of all organic components in the samples. The peak was broader in AS and ASC with markedly lower To values of $304{ }^{\circ} \mathrm{C}$ and $341{ }^{\circ} \mathrm{C}$, respectively, suggesting initial melting of the amorphous materials present in the samples [58]. The corresponding $\Delta \mathrm{H}$ values were $7.5 \mathrm{~J} / \mathrm{g}$ and $12.8 \mathrm{~J} / \mathrm{g}$, respectively. The peak for ASN was narrower, intense, and sharper with To, Tp, and Tc values of $359{ }^{\circ} \mathrm{C}, 393{ }^{\circ} \mathrm{C}$, and $444{ }^{\circ} \mathrm{C}$, respectively, and $\Delta \mathrm{H}$ value of $19.9 \mathrm{~J} / \mathrm{g}$. The highest $\mathrm{T}_{\mathrm{f}}$ value of ASN was due to improved crystalline structure during delignification and hydrolysis, which was consistent with the results of XRD and TGA. The results indicated significant development of thermal resistance in the bionanomaterial after acid treatment, suggesting its potential applicability as a reinforcement agent in heat-resistant solid composite materials [13].

\subsection{Hemolytic activity.}

Hemolytic assays describe the toxicity and biocompatibility of nanomaterials. Kalita et al. (2015) reported the non-toxicity of rice husk cellulose nanoparticles [44]. ASN caused 0\% hemolysis $(\mathrm{H}=0)$ in the erythrocyte solution showing the same light absorption value as the negative control. Hence, the ASN particles were without any hemolytic toxicity in the state they were analyzed and could be considered safe for use in food and pharmaceutical formulations for intravenous usage.

\subsection{Metal sorption property.}

The percentage removal of $\mathrm{Cu}$ (II) and $\mathrm{Pb}$ (II) ions from their aqueous solutions after suspending AS, ASC, and ASN flour particles are plotted in Figure 5. Each sample absorbed $\mathrm{Pb}$ (II) more than $\mathrm{Cu}$ (II), indicating a higher affinity of the former to the cellulose matrix. ASC exhibited the highest absorption of both the bivalent metals $(86.3 \%$ and $93.1 \%)$, marginally followed by AS (84.2\% and $89.1 \%)$.

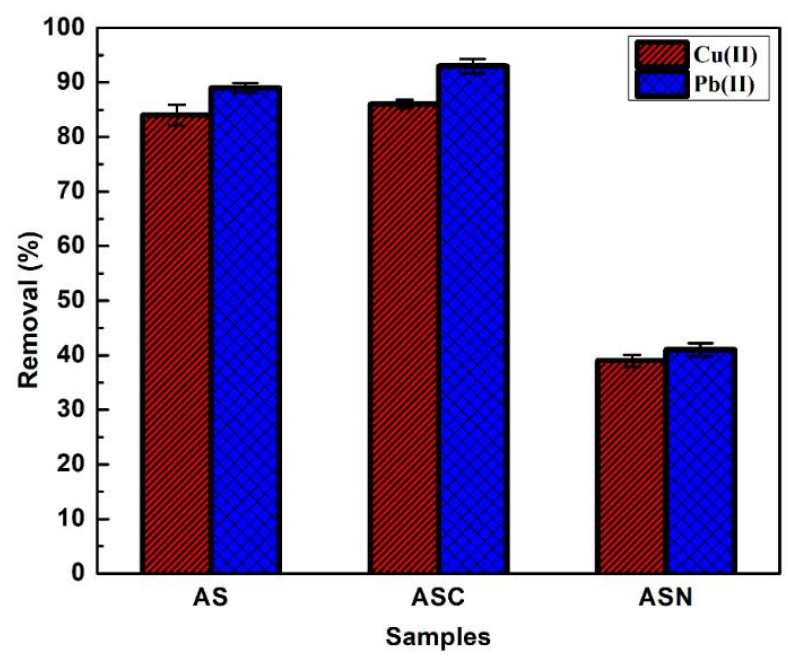

Figure 5. $\mathrm{Cu}(\mathrm{II})$ and $\mathrm{Pb}(\mathrm{II})$ metal removal capacities (\%) of $\mathrm{AS}, \mathrm{ASC}$ and $\mathrm{ASN}$.

This suggested that the cellulose component served as the major metal ion absorption substrate in both samples. An increase in surface area due to exposure of the porous cellulose surface in ASC could have enhanced the removal efficiency. The reduction of ASC to ASN substantially reduced the sorption property (39.0\% and $41.3 \%)$. It suggested that the minor negative potential developed on the ASN particles' surfaces after reduction by sulphuric acid treatment and porosity could not improve its metal sorption capacity as sorption is also 
governed by substrate's surface size integrity was higher in ASC. However, adsorption efficiency may be further improved after suitable composite development with organic or inorganic components, as reported by other authors $[33,35,36]$.

\section{Conclusions}

Nanowhiskers were obtained after hydrolysis of the cellulose with $65 \%$ sulphuric acid. The extraction method could effectively isolate cellulose from the almond shell and gave sufficient yield and purity of nanocrystalline cellulose (Figure 6). The obtained porous beadlike cellulose structures showed good dicationic metal absorption properties. The porosity of ASC can be projected for absorption and filtration materials to treat industry effluent. The isolation method imparted significant thermal resistance in the nanomaterial. The particles were non-toxic to erythrocytes and can be used as an inert bionanomaterial for application in food and pharmacological industries.

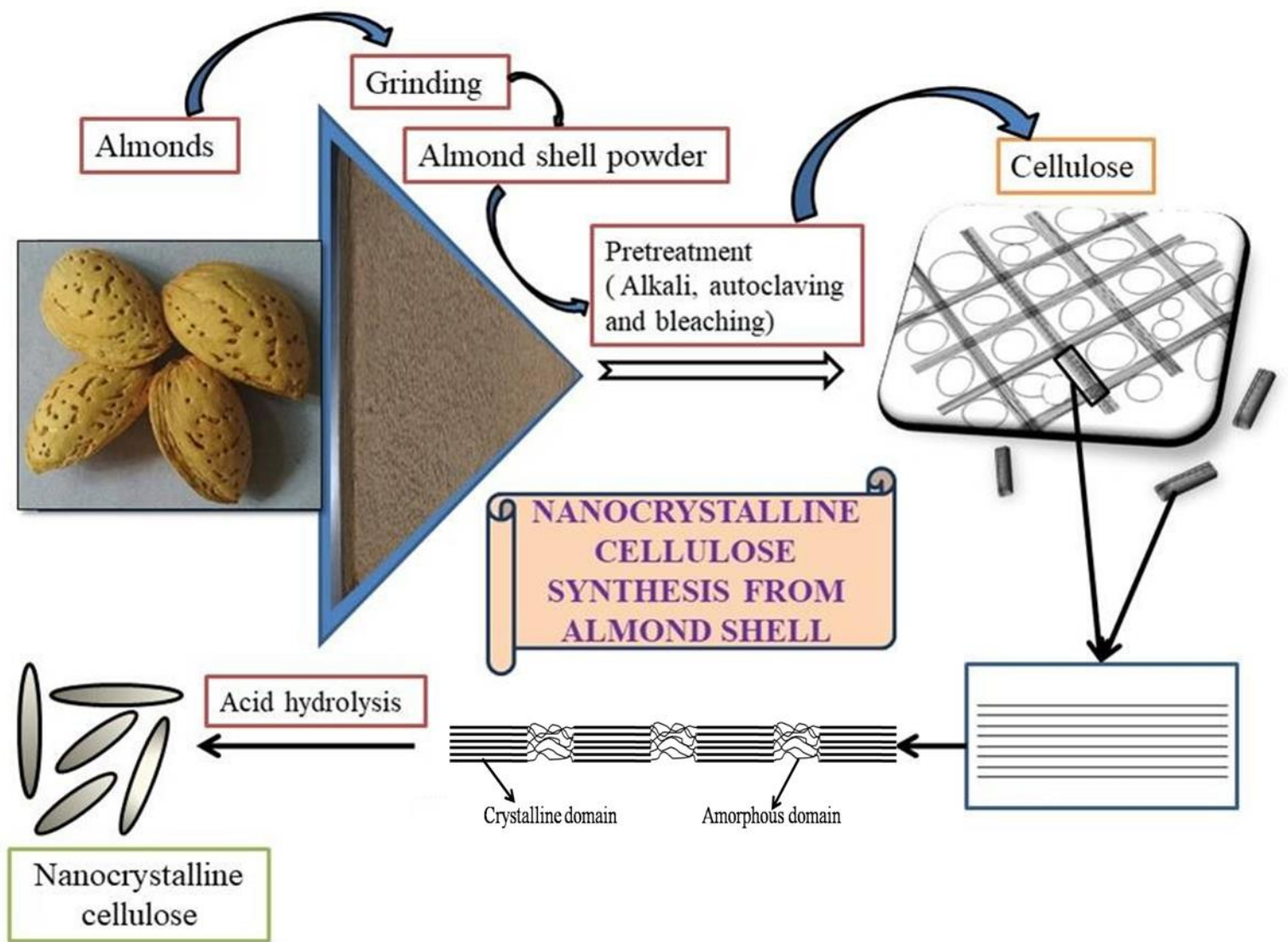

Figure 6. Schematic presentation of the cellulose extraction and nanocrystalline cellulose isolation process.

\section{Funding}

This research received no external funding.

\section{Acknowledgments}

This research has no acknowledgment.

\section{Conflicts of Interest}

The authors declare no conflict of interest. 


\section{References}

1. García, A.; Gandini, A.; Labidi, J.; Belgacem, N.; Bras, J. Industrial and Crop Wastes: A New Source for Nanocellulose Biorefinery. Ind. Crop. Prod. 2016, 93, 26-38, https://doi.org/10.1016/j.indcrop.2016.06.004.

2. George, J.; Sabapathi, S.N. Cellulose Nanocrystals: Synthesis, Functional Properties, and Applications. Nanotech. Sci. Appl. 2015, 8, 45, https://doi.org/10.2147/NSA.S64386.

3. Brinchi, L.; Cotana, F.; Fortunati, E.; Kenny, J.M. Production of Nanocrystalline Cellulose from Lignocellulosic Biomass: Technology and Applications. Carbohydr. Polym. 2013, 94 , 154-169, https://doi.org/10.1016/j.carbpol.2013.01.033.

4. Jonoobi, M.; Oladi, R.; Davoudpour, Y.; Oksman, K.; Dufresne, A.; Hamzeh, Y.; Davoodi, R. Different Preparation Methods and Properties of Nanostructured Cellulose from Various Natural Resources and Residues: A Review. Cellulose 2015, 22, 935-969, https://doi.org/10.1007/s10570-015-0551-0.

5. Zhang, K.; Sun, P.; Liu, H.; Shang, S.; Song, J.; Wang, D. Extraction and Comparison of Carboxylated Cellulose Nanocrystals from Bleached Sugarcane Bagasse Pulp using Two Different Oxidation Methods. Carbohydr. Polym. 2016, 138, 237-243, https://doi.org/10.1016/j.carbpol.2015.11.038.

6. Rezaei, A.; Nasirpour, A.; Fathi, M. Application of Cellulosic Nanofibers in Food Science using Electrospinning and its Potential Risk. Comp. Rev. Food Sci. Food Saf. 2015, 14, 269-284, https://doi.org/10.1111/1541-4337.12128.

7. Zhang, W.; Zhang, Y.; Cao, J.; Jiang, W. Improving the Performance of Edible Food Packaging Films by Using Nanocellulose as an Additive. Int. J. Biol. Macromol. 2021, 166, 288-296, https://doi.org/10.1016/j.ijbiomac.2020.10.185.

8. Rashid, S.; Dutta, H. Characterization of Nanocellulose Extracted from Short, Medium and Long Grain Rice Husks. Ind. Crop. Prod. 2020, 154, 112627, https://doi.org/10.1016/j.indcrop.2020.112627.

9. Rashid, S.; Dutta, H. Physicochemical, Textural and Sensory Properties of Yoghurt as Effected by Carboxymethyl Cellulose from Short, Medium and Long Rice Husks. Plant. Arch. 2020, 20, 2563-2572.

10. Han, S.; Lyu, S.; Chen, Z.; Fu, F.; Wang, S. Combined Stabilizers Prepared from Cellulose Nanocrystals and Styrene-Maleic Anhydride to Microencapsulate Phase Change Materials. Carbohydr. Polym. 2020, 234, 115923, https://doi.org/10.1016/j.carbpol.2020.115923.

11. Bano, S.; Negi, Y.S. Studies on Cellulose Nanocrystals Isolated from Groundnut Shells. Carbohydr. Polym. 2017, 157, 1041-1049, https://doi.org/10.1016/j.carbpol.2016.10.069.

12. Ditzel, F.I.; Prestes, E.; Carvalho, B.M.; Demiate, I.M.; Pinheiro, L.A. Nanocrystalline Cellulose Extracted from Pine Wood and Corncob. Carbohydr. Polym. 2017, 157, 1577-1585.

13. Kampeerapappun, P., Extraction and Characterization of Cellulose Nanocrystals Produced by Acid Hydrolysis from Corn Husk. J. Metal. Material. Mineral. 2015, 25, 19-26, https://doi.org/10.1016/j.carbpol.2016.11.036.

14. Leite, A.L.M.P.; Zanon, C.D.; Menegalli, F.C. Isolation and Characterization of Cellulose Nanofibers from Cassava Root Bagasse and Peelings. Carbohydr. Polym. 2017, 157, 962-970, https://doi.org/10.1016/j.carbpol.2016.10.048.

15. Lu, P.; Hsieh, Y.L., Preparation and Characterization of Cellulose Nanocrystals from Rice Straw. Carbohydr. Polym. 2012, 87, 564-573, https://doi.org/10.1016/j.carbpol.2011.08.022.

16. Mohamed, M.A.; Salleh, W.N.W.; Jaafar, J.; Ismail, A.F.; Abd Mutalib, M.; Mohamad, A.B.; Zain, M.F.M.; Awang, N.A.; Hir, Z.A.M. Physicochemical Characterization of Cellulose Nanocrystal and Nanoporous SelfAssembled CNC Membrane Derived from Ceiba pentandra. Carbohydr. Polym. 2017, 157, 1892-1902, https://doi.org/10.1016/j.carbpol.2016.11.078.

17. Khan, M.N.; Rehman, N.; Sharif, A.; Ahmed, E.; Farooqi, Z.H.; Din, M.I. Environmentally Benign Extraction of Cellulose from Dunchi Fiber for Nanocellulose Fabrication. Int. J. Biol. Macromol. 2020, 153, 72-78, https://doi.org/10.1016/j.ijbiomac.2020.02.333.

18. McCaffrey, Z.; Torres, L.; Flynn, S.; Cao, T.; Chiou, B.S.; Klamczynski, A.; Glenn, G.; Orts, W. Recycled Polypropylene-Polyethylene Torrefied Almond Shell Biocomposites. Ind. Crop. Prod. 2018, 125, 425-432, https://doi.org/10.1016/j.indcrop.2018.09.012.

19. Urrestarazu, M.; Martínez, G.A.; del Carmen Salas, M. Almond Shell Waste: Possible Local Rockwool Substitute in Soilless Crop Culture. Sci. Horticult. 2005, 103, 453-460, https://doi.org/10.1016/j.scienta.2004.06.011. 
20. Demirbas, E.; Kobya, M.K.A.E.; Konukman, A.E.S. Error Analysis of Equilibrium Studies for the Almond Shell Activated Carbon Adsorption of Cr (VI) from Aqueous Solutions. J. Hazard. Material. 2008, 154, 787794, https://doi.org/10.1016/j.jhazmat.2007.10.094.

21. Essabir, H.; Nekhlaoui, S.; Malha, M.; Bensalah, M.O.; Arrakhiz, F.Z.; Qaiss, A.; Bouhfid, R. Bio-composites based on Polypropylene Reinforced with Almond Shells Particles: Mechanical and Thermal Properties. Material. Design 2013, 51, 225-230, https://doi.org/10.1016/j.matdes.2013.04.031.

22. Melhaoui, R.; Miyah, Y.; Kodad, S.; Houmy, N.; Addi, M.; Abid, M.; Mihamou, A.; Serghini-Caid, H.; Lairini, S.; Tijani, N.; Hano, C. On the Suitability of Almond Shells for the Manufacture of a Natural LowCost Bioadsorbent to Remove Brilliant Green: Kinetics and Equilibrium Isotherms Study. Sci. World. J. 2021, 1-13, https://doi.org/10.1155/2021/6659902.

23. Sabir, A.; Altaf, F.; Batool, R.; Shafiq, M.; Khan, R.U.; Jacob, K.I. Agricultural Waste Absorbents for Heavy Metal Removal. In Green Adsorbents to Remove Metals, Dyes and Boron from Polluted Water, Ahamed, I.; Lichtfouse, M.I.; Asiri, A.M., Eds.; Springer, Cham. 2021, 195-228, https://doi.org/10.1007/978-3-03047400-3_8.

24. Li, X.; Liu, Y.; Hao, J.; Wang, W., Study of Almond Shell Characteristics. Materials 2018, 11, 1782, https://doi.org/10.3390/ma11091782.

25. Pirayesh, H.; Khazaeian, A., Using Almond (Prunus amygdalus L.) Shell as a Bio-Waste Resource in Wood $\begin{array}{llllll}\text { Based Composite. } & \text { Composit. } & \text { B: } & \text { Eng. } & \text { 2012, } & \text { 43, }\end{array}$ https://doi.org/10.1016/j.compositesb.2011.06.008.

26. Khili, F.; Borges, J.; Almeida, P.L.; Boukherroub, R.; Omrani, A.D. Extraction of Cellulose Nanocrystals with Structure I and II and Their Applications for Reduction of Graphene Oxide and Nanocomposite Elaboration. Waste Biomas. Valor. 2019, 10, 1913-1927, https://doi.org/10.1007/s12649-018-0202-4.

27. Maaloul, N.; Arfi, R.B.; Rendueles, M.; Ghorbal, A.; Diaz, M. Dialysis-Free Extraction and Characterization of Cellulose Crystals from Almond (Prunus dulcis) Shells. J. Mater. Environ. Sci. 2017, 8, 4171-4181.

28. Urruzola, I.; Robles, E.; Serrano, L.; Labidi, J., Nanopaper from Almond (Prunus dulcis) shell. Cellulose 2014, 21, 1619-1629, https://doi.org/10.1007/s10570-014-0238-y.

29. Peng, B.L.; Dhar, N.; Liu, H.L.; Tam, K.C., Chemistry and Applications of Nanocrystalline Cellulose and its Derivatives: A Nanotechnology Perspective. Canad. J. Chem. Engg. 2011, 89, 1191-1206, https://doi.org/10.1002/cjce.20554.

30. Xie, H.; Du, H.; Yang, X.; Si, C. Recent Strategies in Preparation of Cellulose Nanocrystals and Cellulose Nanofibrils Derived from Raw Cellulose Materials. Int. J. Polym. Sci. 2018, 1-25, https://doi.org/10.1155/2018/7923068.

31. Mohammed, M.A.; Basirun, W.J.; Abd Rahman, N.M.M.; Mohamad Salleh, N. The Effect of Particle Size of Almond Shell Powders, Temperature and Time on the Extraction of Cellulose. J. Natur. Fiber. 2021, 111, https://doi.org/10.1080/15440478.2021.1881689.

32. Mishra, R.K.; Ha, S.K.; Verma, K.; Tiwari, S.K. Recent Progress in Selected Bio-Nanomaterials and Their Engineering Applications: An Overview.J. Sci. Adv. Material. Device. 2018, 3, 263-288, https://doi.org/10.1016/j.jsamd.2018.05.003.

33. Maaloul, N.; Oulego, P.; Rendueles, M.; Ghorbal, A.; Díaz, M. Enhanced Cu (II) Adsorption using Sodium Trimetaphosphate-Modified Cellulose Beads: Equilibrium, Kinetics, Adsorption Mechanisms, and Reusability. Environ. Sci. Pollut. Res. 2020, 1-17, https://doi.org/10.1007/s11356-020-10158-8.

34. Maaloul, N.; Oulego, P.; Rendueles, M.; Ghorbal, A.; Díaz, M. Biopolymer Composite from Cellulose Nanocrystals of Almond (Prunus dulcis) Shell as Effective Adsorbents for $\mathrm{Cu}^{2+}$ ions from Aqueous Solutions. J. Env. Chem. Engg. 2021, 9, 105139, https://doi.org/10.1016/j.jece.2021.105139.

35. Shu, Y.; Ji, B.; Cui, B.; Shi, Y.; Wang, J.; Hu, M.; Luo, S.; Guo, D. Almond Shell-Derived, BiocharSupported, Nano-Zero-Valent Iron Composite for Aqueous Hexavalent Chromium Removal: Performance and Mechanisms. Nanomaterials 2020, 10, 198, https://doi.org/10.3390/nano10020198.

36. Hsini, A.; Essekri, A.; Aarab, N.; Laabd, M.; Addi, A.A.; Lakhmiri, R.; Albourine, A. Elaboration of Novel Polyaniline@Almond shell Biocomposite for Effective Removal of Hexavalent Chromium Ions and Orange G Dye from Aqueous Solutions. Environ. Sci. Pollut. Res. 2020, 1-14, https://doi.org/10.1007/s11356-02008039-1.

37. Johar, N.; Ahmad, I.; Dufresne, A. Extraction, Preparation and Characterization of Cellulose Fibres and Nanocrystals from Rice Husk. Ind. Crop. Prod. 2012, 37, 93-99, https://doi.org/10.1016/j.indcrop.2011.12.016. 
38. Kumar, A.; Negi, Y.S.; Choudhary, V.; Bhardwaj, N.K. Characterization of Cellulose Nanocrystals Produced by Acid-hydrolysis from Sugarcane Bagasse as Agro-waste. J. Material. Phy. Chem. 2014, 2, 1-8, https://doi.org/10.12691/jmpc-2-1-1.

39. Rhim, J.W.; Reddy, J.P.; Luo, X. Isolation of Cellulose Nanocrystals from Onion Skin and their Utilization for the Preparation of Agar-based Bio-nanocomposites Films. Cellulose 2015, 22, 407-420, https://doi.org/10.1007/s10570-014-0517-7.

40. De Oliveira, J.P.; Bruni, G.P.; Lima, K.O.; El Halal, S.L.M.; da Rosa, G.S.; Dias, A.R.G.; da Rosa Zavareze, E., Cellulose Fibers Extracted from Rice and Oat Husks and Their Application in Hydrogel. Food Chem. 2017, 221, 153-160, https://doi.org/10.1016/j.foodchem.2016.10.048.

41. Song, T.; Zhang, Z.; Liu, S.; Chen, J.; Cai, W. Effect of Cultured Substrates on the Chemical Composition and Biological Activities of Lingzhi or Reishi Medicinal Mushroom, Ganoderma lucidum $\begin{array}{lllll}\text { (Agaricomycetes). Int. } \quad \text { J. Medicin. } & \text { Mushroom. } & \text { 2020, 22, }\end{array}$ https://doi.org/10.1615/IntJMedMushrooms.2020037133.

42. AOAC. Association of Official Analytical Chemists. Official Methods of Analysis, 2006, 18th ed. Washington DC US.

43. Segal, L.G.J.M.A.; Creely, J.J.; Martin Jr, A.E.; Conrad, C.M. An Empirical Method for Estimating the Degree of Crystallinity of Native Cellulose using the X-ray Diffractometer. Textil. Res. J. 1959, 29, 786-794, https://doi.org/10.1177/004051755902901003.

44. Kalita, E.; Nath, B.K.; Deb, P.; Agan, F.; Islam, M.R.; Saikia, K., High Quality Fluorescent Cellulose Nanofibers from Endemic Rice Husk: Isolation and Characterization. Carbohydr. Polym. 2015, 122, 308313, https://doi.org/10.1016/j.carbpol.2014.12.075.

45. Ronda, A.; Martín-Lara, M.A.; Dionisio, E.; Blázquez, G.; Calero, M. Effect of Lead in Biosorption of Copper by Almond Shell. J. Taiwan Inst. Chem. Eng. 2013, 44, 466-473,https://doi.org/10.1016/j.jtice.2012.12.019.

46. Nascimento, P.; Marim, R.; Carvalho, G.; Mali, S. Nanocellulose Produced from Rice Hulls and its Effect on the Properties of Biodegradable Starch Films. Material. Res. 2016, 19, 167-174, https://doi.org/10.1590/1980-5373-MR-2015-0423.

47. Neto, W.P.F.; Silvério, H.A.; Dantas, N.O.; Pasquini, D. Extraction and Characterization of Cellulose Nanocrystals from Agro-Industrial Residue-Soy Hulls. Ind. Crop. Prod. 2013,42, 480-488, https://doi.org/10.1016/j.indcrop.2012.06.041.

48. Kunaver, M.; Anžlovar, A.; Žagar, E., The Fast and Effective Isolation of Nanocellulose from Selected $\begin{array}{llll}\text { Cellulosic } & \text { Feedstocks. Carbohydr. } & \text { Polym. } & \text { 2016, 148, }\end{array}$ https://doi.org/10.1016/j.carbpol.2016.04.076.

49. de Morais Teixeira, E.; Bondancia, T.J.; Teodoro, K.B.R.; Corrêa, A.C.; Marconcini, J.M.; Mattoso, L.H.C.; Sugarcane Bagasse Whiskers: Extraction and Characterizations. Ind. Crop. Prod. 2011, 33, 63-66, https://doi.org/10.1016/j.indcrop.2010.08.009.

50. Oun, A.A.; Rhim, J.W., Characterization of Nanocelluloses Isolated from Ushar (Calotropis procera) Seed Fiber: Effect of Isolation Method. Material. Letter. 2016, 168, 146-150, https://doi.org/10.1016/j.matlet.2016.01.052.

51. Andrade-Mahecha, M.M.; Pelissari, F.M.; Tapia-Blácido, D.R.; Menegalli, F.C. Achira as a Source of Biodegradable Materials: Isolation and Characterization of Nanofibers. Carbohydr. Polym. 2015, 123, 406415, https://doi.org/10.1016/j.carbpol.2015.01.027.

52. Alves, L.; Medronho, B.; Antunes, F.E.; Fernández-García, M.P.; Ventura, J.; Araújo, J.P.; Romano, A.; Lindman, B. Unusual Extraction and Characterization of Nanocrystalline Cellulose from Cellulose Derivatives. J. Molecul. Liquid. 2015, 210, 106-112, https://doi.org/10.1016/j.molliq.2014.12.010.

53. Bansal, M.; Chauhan, G.S.; Kaushik, A.; Sharma, A. Extraction and Functionalization of Bagasse Cellulose Nanofibres to Schiff-base based Antimicrobial Membranes. Int. J. Biol. Macromol. 2016, 91, 887-894, https://doi.org/10.1016/j.ijbiomac.2016.06.045.

54. Kargarzadeh, H.; Ahmad, I.; Abdullah, I.; Dufresne, A.; Zainudin, S.Y.; Sheltami, R.M. Effects of Hydrolysis Conditions on the Morphology, Crystallinity, and Thermal Stability of Cellulose Nanocrystals Extracted from Kenaf Bast Fibers. Cellulose 2012, 19, 855-866,https://doi.org/10.1007/s10570-012-9684-6.

55. Wang, Z.; Yao, Z.; Zhou, J.; Zhang, Y. Reuse of Waste Cotton Cloth for the Extraction of Cellulose Nanocrystals. Carbohydr. Polym. 2017, 157, 945-952, https://doi.org/10.1016/j.carbpol.2016.10.044.

56. Moriana, R.; Vilaplana, F.; Ek, M., Cellulose Nanocrystals from Forest Residues as Reinforcing Agents for Composites: A Study from Macro-to Nano-dimensions. Carbohydr. Polym. 2016, 139, 139-149, https://doi.org/10.1016/j.carbpol.2015.12.020. 
57. Mandal, A.; Chakrabarty, D. Isolation of Nanocellulose from Waste Sugarcane Bagasse (SCB) and its Characterization. Carbohydr. Polym. 2011, 86, 1291-1299, https://doi.org/10.1016/j.carbpol.2011.06.030.

58. Nascimento, D.M.; Almeida, J.S.; Dias, A.F.; Figueirêdo, M.C.B.; Morais, J.P.S.; Feitosa, J.P.; Rosa, M.D.F. A Novel Green Approach for the Preparation of Cellulose Nanowhiskers from White Coir. Carbohydr. Polym. 2014, 110, 456-463, https://doi.org/10.1016/j.carbpol.2014.04.053.

59. Wartelle, L. H.; Marshall, W. E. Nutshells as Granular Activated Carbons: Physical, Chemical and Adsorptive Properties. J. Chem. Tech. Biotech. Int. Res. Proces. Env. Clean. Tech. 2001, 76(5), 451-455, https://doi.org/10.1002/jctb.408. 